\section{Cureus

\title{
Tungiasis Presenting as Onychomycosis: Probably the First Report of Flea Infestation of the Nail Observed Using Modified Potassium Hydroxide Mount Technique
}

\author{
Venkataramana Kandi ${ }^{1}$ \\ 1. Microbiology, Prathima Institute of Medical Sciences, Karimnagar, IND \\ $\square$ Corresponding author: Venkataramana Kandi, ramana20021@gmail.com \\ Disclosures can be found in Additional Information at the end of the article
}

\section{Abstract}

Tungiasis is an infection/infestation of the flea Tunga penetrans. These are bloodsucking ectoparasitic insects belonging to the phylum Arthropoda, and they do not possess wings, but they have long legs enabling them to jump up to $30 \mathrm{~cm}$ high. The fleas are usually present on the skin and in the hair of domestic and wild animals and are prevalent throughout the world. They may also be present in an environment consisting of dry sandy soils, and they infect people who walk barefoot and reside in flea-infested areas. Human tungiasis is both an accidental and zoonotic infection, where the fleas enter the human skin and cause severe morbidity if not properly managed. There are a few reports of human tungiasis, most of which were diagnosed with skin infections. This is a first-of-its-kind observation of fleas in the nail, from a patient who is suspected to be suffering from onychomycosis. The nail in this case was processed differently, by using a modified potassium hydroxide $(\mathrm{KOH})$ mount technique.

Categories: Pathology, Infectious Disease, Epidemiology/Public Health

Keywords: tungiasis, human tungiasis, tunga penetrans, flea, onychomycosis, modified koh mount

\section{Introduction}

Tungiasis is an infestation of the sand flea that belongs to the phylum Arthropoda, class Insecta, and order Siphonaptera. It is commonly referred to as chigoe flea, and Tunga penetrans (T penetrans) is its scientific name. These fleas are named differently as Jigger, Nigua, Pico/Pio, Bicho de pie (Spain), Bicho de pe (Portugal), Bichodo porco, Pique, Pulga de areia Kuti,

Received 02/25/2018

Review began $02 / 27 / 2018$ Review ended 02/28/2018 Published 03/05/2018

\section{(c) Copyright 2018}

Kandi. This is an open access article distributed under the terms of the Creative Commons Attribution License CC-BY 3.0., which permits unrestricted use, distribution, and reproduction in any medium, provided the original author and source are credited. Jatecuba, and Sikka in various parts of the world. T penetrans, belongs to the genus Tunga and family Tungidae, which contain obligate hematophagous ectoparasites. There are around 14 species of Tunga fleas, and this is also the smallest known flea, measuring up to $1 \mathrm{~mm}$. Along with T penetrans, only two other species, Tunga trimamillata and Tunga hexalobulata, are known to parasitize animals, with $T$ penetrans being associated with human infections [1-3]. Tungiasis is highly endemic to Trinidad and Tobago, Nigeria, and Brazil, where 50\% people have been noted to be suffering from infections with $T$ penetrans. Tungiasis is an ubiquitous infection spread throughout the world and has been reported from more than 88 countries, including South and Central America, Asia, Africa, and Europe. The flea Tunga penetrans is native to West Indies, Caribbean islands, other regions of Africa (sub-Saharan Africa, Kenya, Uganda), India, Pakistan, Nepal, and Latin American countries [4]. Tungiasis in humans was first reported in the years following $1500 \mathrm{AD}$, when sailors with Christopher Columbus suffered 
skin infections, after they were shipwrecked on an island of Haiti. Fleas responsible for tungiasis have limited jumping/flying abilities $(<30 \mathrm{~cm})$, and therefore most human lesions appear on the skin, below the waist, particularly on the legs. Lesions were also reported from other areas of the body, including the hands, elbow, neck, and face [5]. These fleas like a warm and dry environment and are present in the soil under stables, stock farms, beaches, coastal areas, desert soils, and other sandy soils [6]. Pigs, dogs, cats, rats, sheep, cattle, donkeys, monkeys, birds, and elephants are considered as reservoirs of fleas causing tungiasis [7-8]. Reports of human tungiasis have been recently growing, and there is only one report of human tungiasis from India previously [9-10]. This observation, the first of its kind where the insects were observed in the nail, was performed using a modified potassium hydroxide mount (KOH) technique.

\section{Technical Report}

Patients usually present to the dermatology department with infections/conditions of the skin, hair, and nails. Most of these lesions are attributed to infection with microorganisms, including bacteria, viruses, fungi, and occasionally parasites. Many other skin lesions are due to allergic/hypersensitive reactions and must be cautiously diagnosed ruling out infectious etiology.

Clinical microbiology laboratories receive samples of skin, hair, and nail, and in most instances the microbiologists mostly look for the presence of fungal elements (yeast cells, filamentous fungi). A potassium hydroxide $(\mathrm{KOH})$ mount is routinely performed to see the presence of fungal elements.

Recently, there have been reports of the occurrence of other ectoparasites in the skin, including the mite, which is the causative agent of scabies. A routine $\mathrm{KOH}$ mount may fail to detect the presence of mites, as $\mathrm{KOH}$ acts as a keratinolytic and may immobilize the insects and kill them, making them invisible on microscopy. Technical modifications during the preparation and processing of specimens could increase the chances of finding the parasites [11].

This is a report of a 45-year-old female patient, who presented to the dermatology outpatient department (OPD), with complaints of discoloration of nails (disfiguring and blackening), involving both the hands and the toe nails for three months. The dermatologists suspected a case of onychomycosis (tinea unguium) caused by fungus and sent nail clippings both from the toes and the fingers for further microbiological examination and confirmation.

The nail clippings were observed to be black in color and brittle (Figure 1), in contrast to being hard, white to yellowish in color, and crumbling at the edges when there is a fungal infection. 


\section{Cureus}

\section{FIGURE 1: Infected nail clipping seen as black in color}

The sample was processed for routine $\mathrm{KOH}$ mount (40\%) and observed under a low power (10X) and high power (40X) objective of a compound microscope and was found to be negative for fungal elements.

The sample was then processed by using a modified $\mathrm{KOH}$ mount technique, which revealed various stages of the life cycle of the flea, probably $T$ penetrans. The gravid female flea, which is enlarged and releasing eggs is seen in Figure 2.

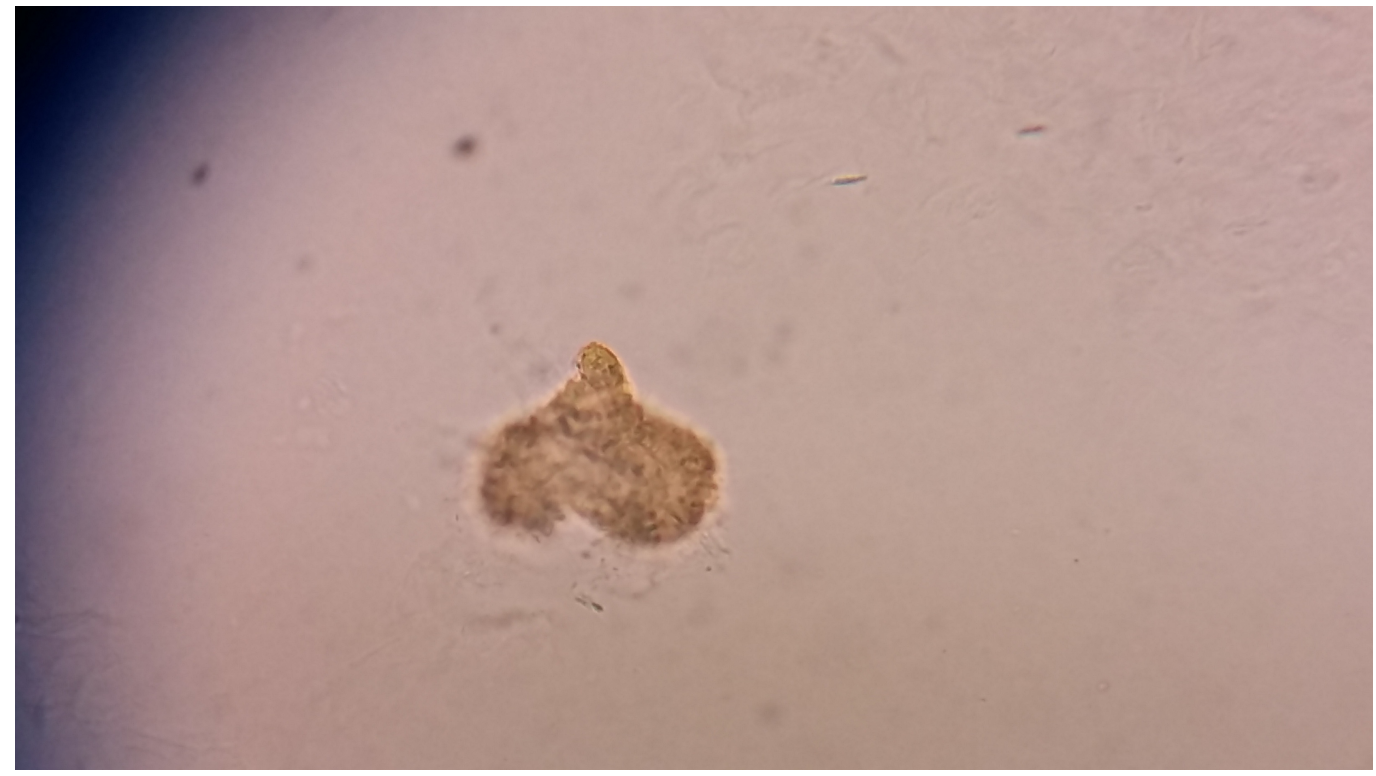

FIGURE 2: A gravid female flea that is enlarged and releasing eggs

Figure 3 shows the larval form of the flea after it hatched out of the egg. 


\section{Cureus}

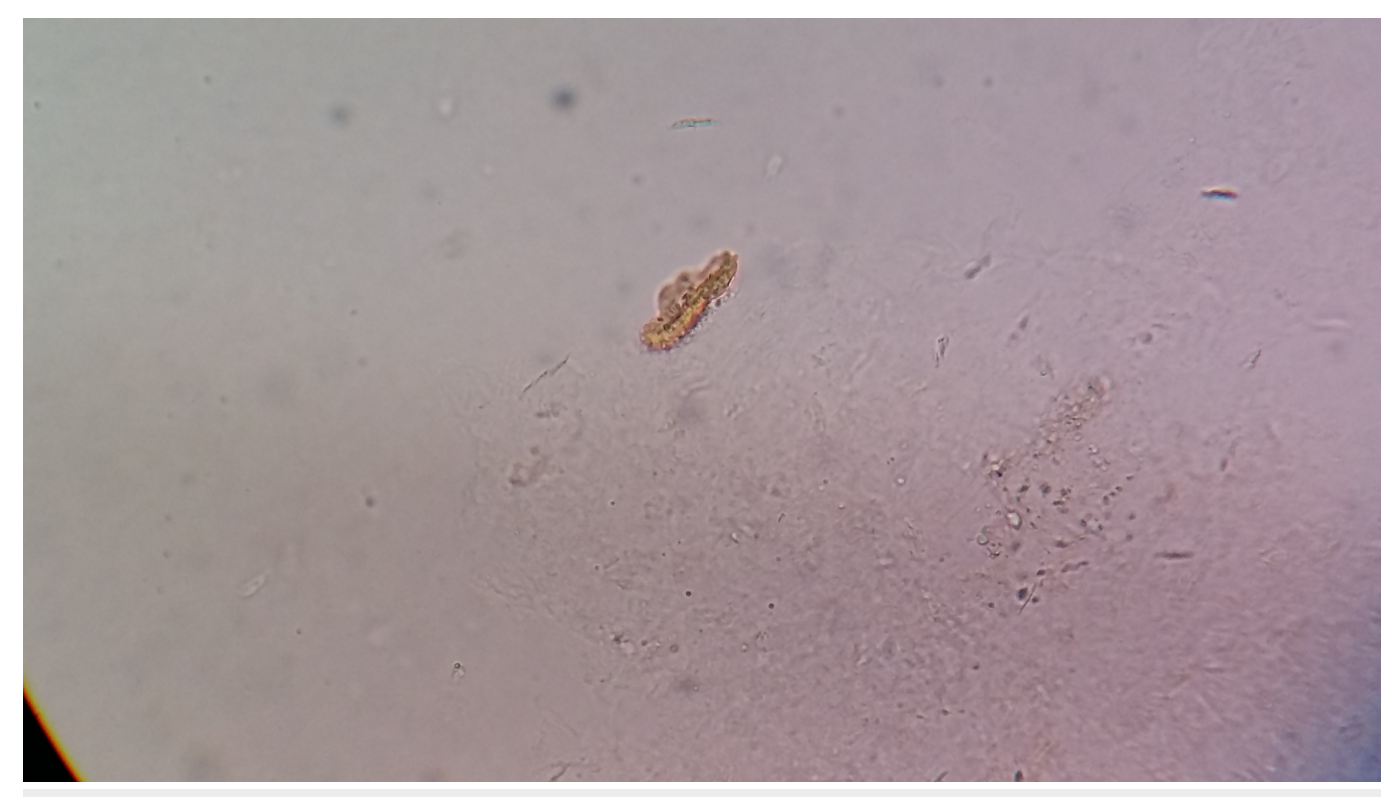

FIGURE 3: Larval form of a flea after it hatched out of an egg

Figure 4 shows the gradual development of the larva into the next stage, the pupa.

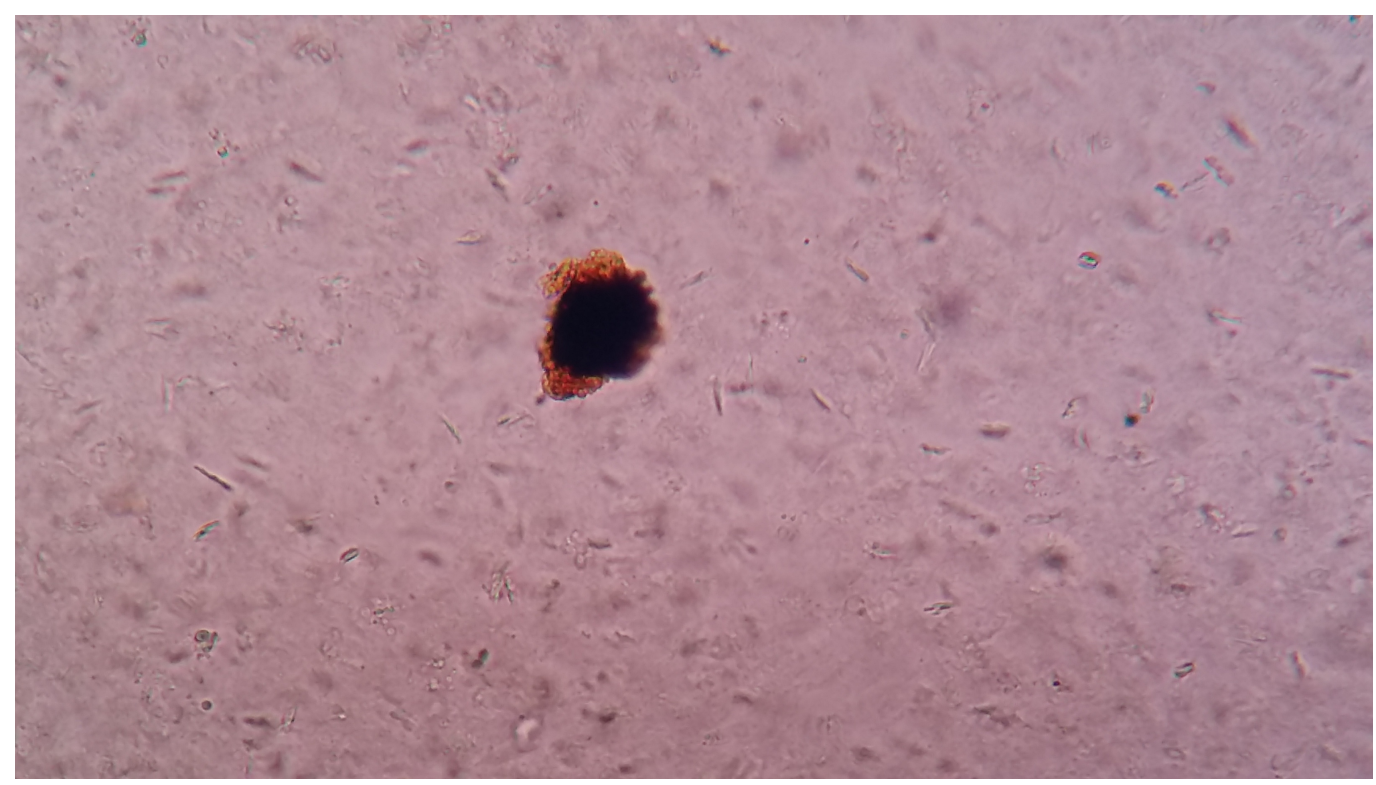

FIGURE 4: Pupa developing from the larval form

Figure 5 shows the pupal form that is ready to release a young adult flea. 


\section{Cureus}

FIGURE 5: A young adult flea ready to be released from the pupa

The young adult flea coming out of the pupa can be seen in Figure 6.

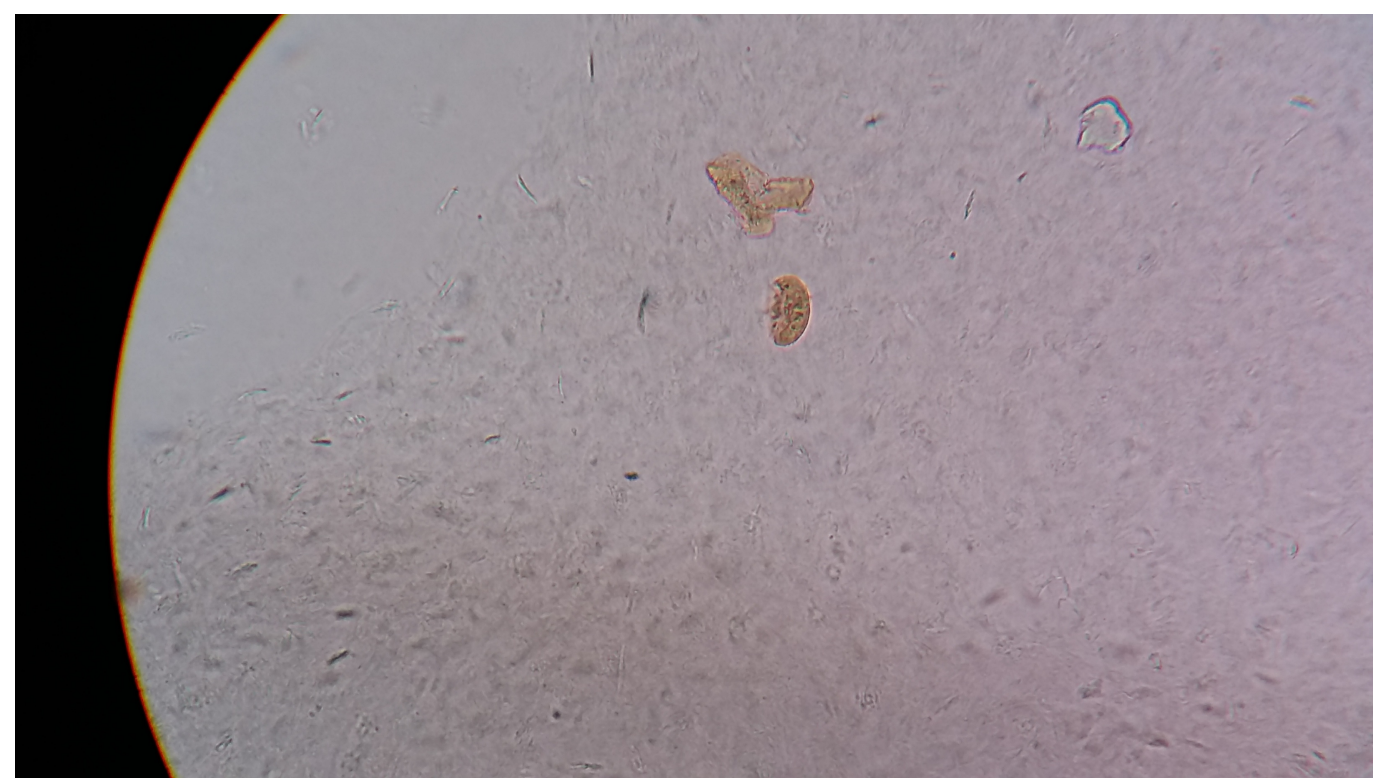

FIGURE 6: A young adult flea after coming out of the pupa

\section{Modified KOH mount technique}

$\mathrm{KOH}$ is an inorganic, colorless, solid chemical, commonly referred to as caustic potash. It is a strong alkaline substance that shows keratinolytic activity and helps in dissolving the hard tissues. It is used in varied concentrations to dissolve human tissues and observe for microorganisms.

Clinical microbiology laboratories use three different concentrations of $\mathrm{KOH}$ : a $10 \% \mathrm{KOH}$ for 
observing skin scrapings, a $20 \% \mathrm{KOH}$ for hair, and a $40 \% \mathrm{KOH}$ for nails. $\mathrm{KOH}$ preparation can be modified to increase the chance of finding microorganisms. Adding di-methyl sulphoxide (solvent) reduces the time of finding microorganisms. To increase the visibility of fungal elements, India ink, Chicago sky blue, and lactophenol cotton blue solution can be added with the $\mathrm{KOH}$ preparation.

An infected nail, when it is hard, takes a lot of time to dissolve even in $40 \% \mathrm{KOH}$, and if kept for longer periods, the $\mathrm{KOH}$ may crystallize making it difficult to observe. $\mathrm{KOH}$, with its corrosive activity, might also cause damage to the microorganisms and other parasitic forms, if any, present in the specimen as noted by a previous research report [12]. To improve the chances of finding both the parasitic forms and the microorganisms, I suggest an alternate and modified $\mathrm{KOH}$ preparation technique for nails.

The infected nail clippings should be first placed in normal saline and kept at room temperature for four hours. After this, the nail clippings should be placed in $20 \% \mathrm{KOH}$ for two hours. A simple mount of the nail material should then be made on a clean and grease-free slide. Then a coverslip should be applied, and the nail should be observed under a low power (10X) and high power (40X) objective of a compound microscope. This procedure reduces the time of dissolving of the nail, does not destroy the microorganisms or parasites present in the specimen, and could be effective in demonstrating the parasites, if any, present in the nail.

\section{Discussion}

Human tungiasis is an ectoparasitic infection, which usually presents as redness of the skin with swelling and very itchy and painful/painless lesions. The fleas burrow themselves under the epidermis and move deeper into the upper dermis, near the blood vessels and feed on blood. The adult female flea lays around 100 eggs (neosome: female flea filled with eggs), which in the course of time hatch into larvae, develop into pupae and later into adults. The burrowed fleas normally die within two weeks, sloughing off the affected skin. The fleas release a substance before sucking the blood, which could be responsible for local allergic reactions. Human skin lesions usually appear as white and swollen affected areas with a black and raised center. The lesions show severe inflammation and ulcerate, and they can result in severe pain and itching. In untreated cases, the lesions can develop secondary bacterial infections, including tetanus, pyogenic infections, and gangrene [12].

Multiple skin lesions resembling the common skin infections caused by other microorganisms can be noted in patients suffering from tungiasis. Careful dermoscopic examinations could increase the chance of diagnosis [13]. Complications of human tungiasis include severe tissue damage, intraepithelial abscess, nail deformation, suppuration, and autoamputation of the affected digits (ainhum) [14].

Tungiasis is more common in people who are poor, walk barefoot, reside in sandy soil conditions, and it is more common during the dry seasons. It is seen in varied age groups with the geriatric age group being more susceptible to infestation [15].

A recent report from India had communicated the occurrence of tungiasis among the troops who were serving in the UN peace keeping forces in Central Africa. This report had also observed that more than $69 \%$ of the patients had secondary bacterial infection [16]. Recently, the first case from Nepal was reported, which was also the first one to report infection of the genitals by $T$ penetrans [17].

Infection among children could be responsible for severe morbidity as evidenced by a recent research by Wiese S et al., from Kenya, who evaluated the dermatology life quality index (DLQI) 
of the children suffering from tungiasis. The same study had noted that the severity of infection correlated well with the number of live fleas under the skin and the chronicity of infection [18].

Tungiasis is a potential zoonotic infection transmitted from animals (pigs, dogs, cats, etc.) to humans. The knowledge of infection, associated clinical features, and public health awareness regarding the transmission of tungiasis from household animals among the study population was reported by Mutebi F et al. [19].

Recently, there has been a first-of-its-kind report of tungiasis from a European country, Portugal. This communication sensitizes tungiasis, as a potential infection among the travelers returning from the endemic regions and the importance of physician awareness of its clinical presentation [20].

In this particular case, the clinical presentation was atypical (not involving the skin) with black discoloration of the nail, with the presence of morphological forms resembling the flea, and a routine $\mathrm{KOH}$ mount was negative for any fungal elements.

\section{Conclusions}

In the era of emergence and re-emergence of microbial infectious agents, it is important for clinicians and dermatologists to continually update themselves and manage the patients appropriately. Clinical microbiology laboratory personnel need to employ improved and modified laboratory techniques to increase the chances of finding parasites. As noted in the present case, the routine microscopic examination failed to show the presence of parasitic forms, whereas the modified $\mathrm{KOH}$ mount technique revealed different stages of the life cycle of the flea.

\section{Additional Information \\ Disclosures}

Human subjects: Consent was obtained by all participants in this study. Animal subjects: All authors have confirmed that this study did not involve animal subjects or tissue. Conflicts of interest: In compliance with the ICMJE uniform disclosure form, all authors declare the following: Payment/services info: All authors have declared that no financial support was received from any organization for the submitted work. Financial relationships: All authors have declared that they have no financial relationships at present or within the previous three years with any organizations that might have an interest in the submitted work. Other relationships: All authors have declared that there are no other relationships or activities that could appear to have influenced the submitted work.

\section{Acknowledgements}

I would like to acknowledge the support of my colleagues, Dr. Padmavali P, Dr. Ritu Vaish, Dr. Sandhya, and Ms. Padmajakshi, and my senior professor Dr. B Mohan Rao for their continuous support and encouragement.

\section{References}

1. Linardi PM, de Avelar DM: Neosomes of tungid fleas on wild and domestic animals . J Parasitol Res. 2014, 113:3517-3533. 10.1007/s00436-014-4081-8

2. Beaucournu JC, Degeilh B, Mergey T, Muñoz-Leal S, González-Acuña D: The genus Tunga Jarocki, 1838 (Siphonaptera: Tungidae). I - Taxonomy, phylogeny, ecology, pathogenic role [Article in French]. Parasite. 2012, 19:297-308. 10.1051/parasite/2012194297

3. Mutebi F, Krücken J, Mencke N, Feldmeier H, von Samson-Himmelstjerna G, Waiswa C: Two 
severe cases of tungiasis in goat kids in Uganda. J Insect Sci. 2016, 16:34.

10.1093/jisesa/iew016

4. Pampiglione S, Fioravanti ML, Gustinelli A, Onore G, Mantovani B, Luchetti A, Trentini M: Sand flea (Tunga spp.) infections in humans and domestic animals: state of the art . Med Vet Entomol. 2009, 23:172-86. 10.1111/j.1365-2915.2009.00807.x

5. Heukelbach J, Wilcke T, Eisele M, Feldmeier H: Ectopic localization of tungiasis. Am J Trop Med Hyg. 2002, 67:214-6.

6. Linardi PM, Calheiros CM, Campelo-Junior EB, Duarte EM, Heukelbach J, Feldmeier H: Occurrence of the off-host life stages of Tunga penetrans (Siphonaptera) in various environments in Brazil. Ann Trop Med Parasitol. 2010, 104:337-45. 10.1179/136485910X12743554759902

7. Mutebi F, Krücken J, Feldmeier H, et al.: High intensity of Tunga penetrans infection causing severe disease among pigs in Busoga, South Eastern Uganda. BMC Vet Res. 2017, 13:206. 10.1186/s12917-017-1127-z

8. Heukelbach J, Bonow I, Witt L, Feldmeier H, Fischer P: High infection rate of Wolbachia endobacteria in the sand flea Tunga penetrans from Brazil. Acta Trop. 2004, 92:225-30. 10.1016/j.actatropica.2004.08.005

9. Veraldi S, Nazzaro G: Cutaneous larva migrans and tungiasis: infestations of the affluent society. G Ital Dermatol Venereol. 2018 , 10.23736/S0392-0488.18.05901-1

10. Sane SY, Satoskar RR: Tungiasis in Maharashtra (a case report). J Postgrad Med. 1985, 31:121.

11. Kandi V: Laboratory diagnosis of scabies using a simple saline mount: a clinical microbiologist's report. Cureus. 2017, 9:e1102. 10.7759/cureus.1102

12. Heukelbach J, Jackson A, Ariza L, Calheiros CM, Soares VL, Feldmeier H: Epidemiology and clinical aspects of tungiasis (sand flea infestation) in Alagoas State, Brazil. J Infect Dev Countries. 2007, 1:202-209.

13. Kosumi H, Iwata H, Miyazawa H, et al.: Dermoscopic features of tungiasis . J Eur Acad Dermatol Venereol. 2018, Accessed: March 5, 2018: 10.1111/jdv.14863

14. Wiese S, Elson L, Reichert F, Mambo B, Feldmeier H: Prevalence, intensity and risk factors of tungiasis in Kilifi County, Kenya: I. Results from a community-based study. PLoS Negl Trop Dis. 2017, 11:e0005925. 10.1371/journal.pntd.0005925

15. Darmstadt GL, Francis JS: Tungiasis in a young child adopted from South America . Pediatr Infect Dis J. 2000, 19:485-7.

16. Sood A, Raman DK, Joshi RK, Gupta D: Tungiasis: outbreak investigation of a zoonosis during overseas deployment. Med J Armed Forces India. 2017, 73:375-379.

10.1016/j.mjafi.2017.08.011

17. Shrivastav S, Adhikari RC: Tungiasis: a rare parasitic infestation in genitals of a native male from Kathmandu. J Nepal Health Res Counc. 2018, 15:295-297.

18. Wiese S, Elson L, Feldmeier H: Tungiasis-related life quality impairment in children living in rural Kenya. PLoS Negl Trop Dis. 2018, 12:e0005939. 10.1371/journal.pntd.0005939

19. Mutebi F, Krücken J, von Samson-Himmelstjerna G, et al.: Animal and human tungiasisrelated knowledge and treatment practices among animal keeping households in Bugiri District, South-Eastern Uganda. Acta Trop. 2018, 177:81-88.

10.1016/j.actatropica.2017.10.003

20. Santos RP, Resende C, da Luz Duarte M, Brito C: Tungiasis: a poorly-known diagnosis in Europe. Two paradigmatic cases from Portugal. Acta Dermatovenerol Alp Pannonica Adriat. 2017, 26:115-117. 10.15570/actaapa.2017.33 